\title{
Nesne Tabanlı Sınıflandırma Yönteminde Sentinel-2A Uydu Görüntüleri Kullanılarak Tarımsal Ürün Desenlerinin Belirlenmesi; Konya - Karapınar Örneği
}

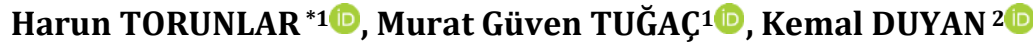 \\ ${ }^{1}$ Toprak Gübre ve Su Kaynakları Merkez Araştırma Enstitüsü Müdürlügü, Ankara, Türkiye \\ ${ }^{2}$ Toprak Su ve Çölleşme ile Mücadele Araştırma Enstitüsü Müdürlügü, Konya, Türkiye
}

Anahtar Kelimeler:

Nesne tabanlı

Sentinel-2A

Siniflandirma

Ürün deseni

\begin{abstract}
ÖZ
Tarımsal ürün desenlerinin belirlenmesi, uzaktan algılama teknolojisinin tarımda kullanım alanlarına örnek olabilecek çalıșmaların bașında gelmektedir. Tarımsal ürünlere ait verim ve rekolte tahminleri, ürün gelişimlerinin takibi ve tarımsal planlamalara yön vermek açısından tarımsal ürün desenini yansıtan tematik haritalar önemle kullanılan altlık verilerdir.

Bu çalışma ile Konya ili Karapınar ilçesinin yüksek çözünürlüklü Sentinel-2A uydu görüntüleri kullanılarak nesne tabanlı sınıflandırma yöntemine göre tarımsal ürün deseni belirlenmiştir. Çoklu çözünürlüklü bölütleme algoritması kullanılarak tarım parselleri sınırlarının oluşturulduğu çalışmada, bölütleme algoritmasına ait en uygun ölçek, şekil ve yoğunluk parametreleri belirlenmiştir. Bölütlerin sınıflandırması için en yakın komşuluk algoritması kullanılmıștır. Sınıflandırmayı kolaylaştırmak açısından, araziden elde edilen eğitim ve test verilerinin yanında NDVI ve DDVI gibi farklı indisler yardımcı veriler olarak kullanılmıştır.

Sınıflandırılmıș tematik haritanın Genel Doğruluk Oranı \% 82, buna karşılık gelen Kappa Katsayısı Oranı ise 0,76 olarak hesaplanmıș olup, sınıflandırma performansının çok iyi düzeyde olduğu tespit edilmiştir. Buna göre tarımsal ürün desenlerinin belirlenmesinde nesne tabanlı sinıflandırma yönteminin yüksek doğrulukta sonuçlar verdiği görülmüştür.
\end{abstract}

\section{Determination of Agricultural Crop Patterns Using Sentinel-2A Satellite İmages in Object-Based Classification Method; A Case Study of Konya-Karapınar}

\author{
Keywords: \\ Object-based \\ Sentinel-2A \\ Classification \\ Crop pattern
}

\begin{abstract}
Determination of agricultural crop patterns is one of the studies that can be an example of the use of remote sensing technology in agriculture. Thematic maps reflecting the agricultural crop pattern are important used of base data in terms of yield and harvest estimates of agricultural crops, monitoring crop developments and directing agricultural planning.

With this study, The agricultural crop pattern was determined using high resolution Sentinel-2A satellite images according to the object-based classification method in district of Karapınar in Konya. In the study where the boundaries of agricultural parcels were created using the multiresolution segmentation algorithm, the most suitable scale, shape and density parameters of the segmentation algorithm were determined. The Nearest Neighborhood algorithm was used for the classification of the segments. In order to facilitate classification, different indices such as NDVI and DDVI were used as auxiliary data besides training and test data obtained from the field.

General Accuracy ratio of the classified thematic map 82\%, its corresponding Kappa coefficient ratio 0,76 were calculated and the classification performance was found to be at a very good level. Accordingly, it has been observed that the object-based classification method gives high accuracy results in determining the patterns of agricultural crops.
\end{abstract} Konya- Karapınar örneği. Türkiye Uzaktan Algılama Dergisi, 3(2), 36-46. 


\section{GíRiş}

Tarımda üretim artışının ve verimliliğin sağlanmasında teknolojilerin kullanılması büyük kolaylıklar sağlamaktadır. Bu teknolojilerden biri olan Uzaktan Algılamanın (UA) en yaygın olarak kullanıldığı alanların başında tarımsal uygulamalar gelmektedir. UA teknolojisi araziler üzerinde sağladığı güncel bilgiler ile ulaşılmak istenen amaca daha hızlı, daha ucuz, daha az insan gücü ile ulaşılması ve kolay güncellenebilir veriler üretmesi bakımından diğer yöntemlere göre büyük üstünlük sağlamaktadır. Nesnelerle direkt temas etmeden fiziksel özellikleri hakkında bilgi elde etme bilimi olarak tanımlanan UA tekniği ile arazilerin farklı mekansal, spektral, radyometrik ve zamansal çözünürlüklerde görüntülenmesi ve izlenmesi mümkün olabilmektedir (Çölkesen, 2009). Tarımda UA teknolojisinin kullanıldığı en önemli konuların başında uydu görüntüleri yardımıyla bitki gelişimlerinin izlenmesi, bitki hastalık ve zararlıların takibi, biyokütle, evapotranspirasyon, ürün verim tahminlerinin yapılmasının yanında arazi örtüsü / arazi kullanım türleri ve özellikle tarımsal ürün desenlerinin belirlenmesi gibi tarımsal ekosistem çalışmaları gelmektedir (Wesseling \& Fedes, 2006). Tarım arazilerindeki ürün desenlerinin belirlenmesi çalıșmalarında, UA'nın temel adımlarından biri olan uydu görüntülerinin sinıflandırılması, sıklıkla başvurulan yöntemlerden birisidir. Sinıflandırma; uydu görüntüsündeki homojen piksel gruplarının, görüntü yorumlama teknikleri kullanılarak ilgili yeryüzü kullanım türleri özelliklerine ayrılması işlemidir (Chandra \& Ghosh, 2007). Bu sinıflandırmalar sayesinde tespit edilen mevcut bitki örtüsü alanlarına ait tematik haritalar, tarım alanlarının planlanması, yapılacak yatırım ve uygulanacak yönetimin seçiminde yol gösterici olacak en önemli unsurlardan birini oluşturmaktadır.

Teknolojinin hızla geliştiği günümüzde, görüntü sınıflandırma teknikleri sınıflamadaki doğruluğu daha yukarılara taşıyabilmek için sürekli kendini yenileyerek gelişmektedir. Piksel tabanlı sınıflandırmalarda verinin işlenmesindeki güçlükler ve sınıflandırma doğruluğunun tartışılması karşısında, nesne (obje) tabanlı sınıflandırma teknikleri gelişmiştir. Bunu günümüzde makine öğrenme ve derin öğrenme, yapay zekaya bağlı olarak yapay sinir ağlarına dayalı teknikler takip etmekte olup, bu ise gelişmeleri farklı bir boyuta taşımaktadır.

Görüntü sınıflandırmalarına dayalı olarak tarımsal araziler üzerinde bitkisel üretim alanlarının belirlenmesinde başta nesne tabanlı sınıflandırma tekniği olmak üzere farklı çözünürlüklerde görüntüler ve farklı sinıflandırma yöntemleri kullanılmaktadır.

Delen ve Şanll, (2017)'de İzmir ili, Menemen İlçesinin kuzeyinde yer alan tarım arazilerine ait ürün desenlerinin tespitine yönelik yapmış oldukları çalışmada, nesne tabanlı sınıflandırma yöntemini uygulamışlardır. 2014 yılına ait RapidEye uydusu tarafindan sağlanan görüntüleri kullandıkları çalışmalarında, alanın tarımsal ürün desenini; mısır, pamuk, zeytin, ayçiçeği, bağ, bostan ve yonca olarak belirlemişlerdir. Çalışma sonucunda elde ettikleri ürün desenine ait tematik haritanın genel doğruluk ve kappa katsayısını sırası ile \% 93,33 ve 0,917 olarak hesaplamışlardır. Vuolo ve ark. (2018) Avusturya'da yaptıkları bir çalışmada, alana ait tarımsal ürün deseninin belirlenmesinde, Sentinel-2 uydu görüntülerini kullanmışlardır. 2016 ve 2017 yıllarını kapsayan iki yıllık uydu görüntülerini kullanarak yapmıș oldukları sınıflandırmada, ürün desenini 9 farklı tarımsal ürün grubu olarak belirlemişlerdir. Sentinel-2 uydu görüntülerinin farklı yıllarda verdiği sınıflandırma sonuçlarının güvenirliliğini karşılaştırdıkları bu çalışmada, çoklu-zamansal görüntü kullanımının, 2016 ve 2017 yılları için benzer eğilimlerle ürün tipi sinıflandırmasında doğruluğu arttırdığını belirlemişlerdir. Çalışma alanı için elde ettikleri tematik haritaların genel doğruluk oranlarını; 2016 yılı için \%95, 2017 yılı için ise \%96 olarak hesaplamışlardır.

Everitt ve ark. (2005) Amerika Birleşik Devletlerinin Teksas eyaletinin kuzeybatısında kamış (Arundo donax L.) ekili alanların tespiti için yüksek çözünürlüklü Quickbird uydu verisini kullanarak ayırt edilebilirliğini ortaya koymuşlardır. Denetimsiz sınıflandırma tekniğinin kullanıldığı çalışmada kamış ekili alanları kendi içerisinde üç farklı sınıf olarak sınıflandırmışlar. Doğruluk değerlendirmesinde üretici ve kullanıcı doğruluklarını sırası ile \% 86 ile \% 100 olarak hesaplamışlar.

Bu çalışmada Konya ili, Karapınar ilçesinde en fazla ekim alanı bulan başta mısır ekili alanlar olmak üzere, tarımsal ürünlere ait üretim desenlerinin uydu görüntüleri kullanılarak sınıflandırılması yapılmıştır. Yüksek çözünürlüklü Sentinel-2A uydu görüntüleri ve eCognition paket programının kullanıldığı bu çalışmada, nesne tabanlı görüntü sınıflandırma yöntemi uygulanmıştır.

\section{YÖNTEM}

\section{1. Çalışma alanı}

Çalışma alanı Konya iline ait Karapınar ilçesidir (Şekil 1). Karapınar ilçesi, $33^{\circ} 09^{\prime}$ ve $33^{\circ} 90^{\prime}$ doğu meridyenleri ile $37^{\circ} 45^{\prime}$ ve $38^{\circ} 01^{\prime}$ kuzey paralelleri arasında olup, il merkezine olan uzaklığ 102 km'dir. Yağışın az, sıcaklık ve buharlaşmanın yüksek olduğu çalışma alanında, yeraltı sularının fazlaca kullanılmasına bağlı olarak, başta mısır olmak üzere ayçiçeği, pancar, yonca ve fiğ gibi sulu tarım ürünleri yoğun olarak ekilmektedir. Ülke genelinde \% 18 oranı ile en fazla mısır ekili alana sahip ilimiz 
Konya'dır (URL-1). Karapınar ilçesi ise Konya ilinde mısır ekim alanı olarak en fazla üretimin yapıldığı ilçedir. Yaklaşık olarak 218401.53 hektar yüzölçümüne sahip olan ilçede, tarım alanları toplam alanın \% 62.97 'sini olușturarak 137543 hektar alana sahiptir. İlçede en fazla üretim alanı bulan ürünler ise mısır, ayçiçeği, buğday ve arpadır.

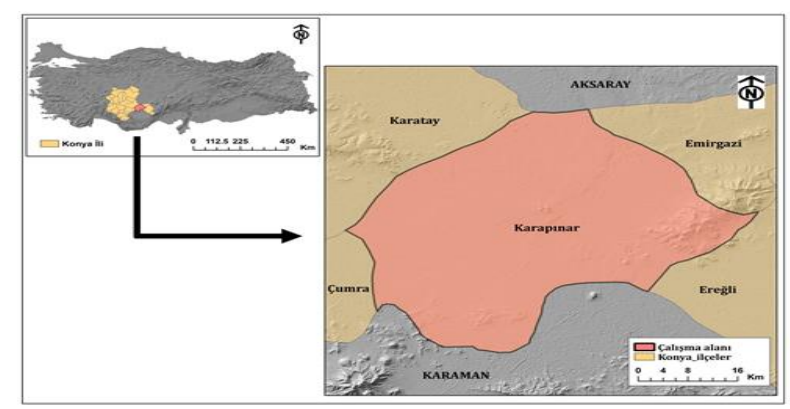

Şekil 1. Çalışma alanı

\subsection{Uzaktan algılama (uydu) verileri}

Çalışma alanının başta mısır olmak üzere ürün deseninin belirlenmesine yönelik yapılan görüntü sinıflandırması için Sentinel-2A uydu görüntüleri ve bu görüntülerden elde edilen bitki indisleri materyal olarak kullanılmıștır.

Sentinel-2 uydusu, orta mekânsal çözünürlüğe sahip olan ve Avrupa Uzay Ajansı (ESA) tarafından geliştirilen çok bantlı bir araçtır. Sentinel-2 uydu görüntüleri toplamda 13 farklı banttan oluşmasına rağmen, özellikle hem kısa dalga hem de yakın kızılötesi bantların koyu yeșil görünen bitki örtüsünü vurgulamada başarılı olmasından dolayı çoğunlukla bitki gelişiminin izlenmesi gibi tarımsal uygulamalarda sirası ile B2, B3, B4, B8 ve B11 (mavi (B), yeşil (G), kırmızı (R), yakın kızılötesi (NIR) ve kısadalga kızılötesi (SWIR) bantları kullanılmaktadır (URL-2) (Tablo 1).

Tablo 1. Sentinel-2 uydu görüntüleri, bantlara göre çözünürlükleri ve kullanım alanları (URL-3; URL-4)

\begin{tabular}{|c|c|c|c|}
\hline Bant & Açıklama & $\begin{array}{c}\text { Mekansal } \\
\text { Çözünürlük } \\
\text { (m) }\end{array}$ & $\begin{array}{c}\text { Kullanım } \\
\text { Alanları }\end{array}$ \\
\hline B1 & Ultra mavi & 60 & \multirow{7}{*}{$\begin{array}{c}\text { Kentsel } \\
\text { B12, B11, B4 } \\
\text { Tarım } \\
\text { B2, B3, B4, B8, } \\
\text { B11 }\end{array}$} \\
\hline B2 & Mavi & 10 & \\
\hline B3 & Yeşil & 10 & \\
\hline B4 & Kırmızl & 10 & \\
\hline B5 & (VNIR)* & 20 & \\
\hline B6 & (VNIR) & 20 & \\
\hline B7 & (VNIR) & 20 & \\
\hline B8 & (VNIR) & 10 & \multirow{6}{*}{$\begin{array}{c}\text { Atmosferik } \\
\text { B3,B8,B8A,B11,B } \\
12\end{array}$} \\
\hline B8A & (VNIR) & 20 & \\
\hline B9 & (SWIR) $^{* *}$ & 60 & \\
\hline B10 & (SWIR) & 60 & \\
\hline B11 & (SWIR) & 20 & \\
\hline B12 & (SWIR) & 20 & \\
\hline
\end{tabular}

* Görünür ve yakın kızılötesi

** Kısa dalga kızılötesi
10, 20 ve 60 metre yersel çözünürlüklere sahip olan bu görüntüler zamansal olarak her 5 günde bir çekim yapılmaktadır (URL-5).

Optik uydu görüntü tipinde olan bu görüntüler, atmosferik şartlardan etkilendikleri için çekim yapılan bütün görüntüler kullanılamamaktadır. Özellikle uydu görüntülerindeki bulutluluk oranları bu görüntülerin tarımsal uygulamalarda sağlıklı kullanımlarını kısıtlamaktadır.

Çalışmada Sentinel-2A uydu görüntülerinin atmosfer altı yansıtım değerlerini içeren seviye $2 \mathrm{~A}$ görüntüleri kullanılmış olup, bu görüntüler URL-6 sitesinden ücretsiz erişim yoluyla temin edilmiștir.

Görüntü sınıflandırmasındaki doğruluk oranını arttırmak amacıyla uydu görüntülerinin farklı bantları kullanılarak, NDVI (Normalized Difference Vegetation Index) ve DDVI (Difference Difference Vegetation Index) indisleri elde edilmiş ve yardımcı veriler olarak kullanılmıştır.

\subsection{Arazi verileri}

Görüntü sınıflandırmasında kullanılmak üzere arazi verilerine ihtiyaç duyulmuștur. Karapınar ilçesinin ürün desenini yansıtan (Mısır, Ayçiçeği, Buğday-Arpa, Mera, Pancar ve Yonca-Fiğ) tarım parsellerinden GPS (Global Positioning System) aleti yardımıyla ürün koordinat bilgileri noktasal olarak toplanmıştır. $\mathrm{Bu}$ noktasal bilgilerin \% 16 'sı doğrulama amaciyla test verisi olarak, geri kalan noktalar ise sınıflandırmada eğitim verisi olarak kullanılmıştır.

\subsection{Metot}

\subsection{1. Ön hazırlık}

Bitkilerin elektromanyetik enerjiyi görünür bölge dışında kalan yakın kızılötesi bölgesinde neredeyse hiç kullanmadan yansıtmaları ve bu özellikleri nedeniyle uydu görüntülerinde diğer nesnelerden kolaylıkla ayırt edilebilmelerinden dolayı, görünür B2, B3, B4 (mavi (B), yeşil (G), kırmızı (R)) bantları ile yakın kızı̈ötesi B8 (NIR) bantı, çalışmada kullanılmak üzere uygun bantlar olarak tespit edilmiştir. Bant bazında erişim sağlanan uydu görüntülerinin çok bantlı görüntü yapısına dönüştürülmesi için, Erdas Imagine programında katman birleștirme (layer stack) eklenti modülü kullanılarak, seçilen dört banta birleștirme işlemi uygulanmıştır. Çalışmada Sentinel-2A uydu görüntülerinin atmosfer altı yansıtım değerlerini içeren $2 \mathrm{~A}$ seviye görüntüleri kullanılmış, bunlar bulutluluk tespiti ve atmosferik düzeltmesi ile birlikte eğim vb. etkilerin giderildiği görüntülerdir (Drusch vd., 2012). Aynı zamanda UTM (Universal Transverse Merceator) projeksiyon sisteminin tanımlanmış olduğu görüntülerdir. 


\subsubsection{Nesne tabanlı sınıflandırma yöntemi}

Yeryüzü objelerine ilișkin bilgi çıkarımında en sık kullanılan yöntem, uydu görüntülerini kullanarak elde edilen görüntü sınıflandırmasıdır. Özellikle bitkisel üretim alanlarının belirlenmesine bağlı olarak ürün deseni tespitleri uzaktan algılanmış uydu görüntülerinin sinıflandırılması ile yaygın olarak yapılmaktadır. Sınıflandırma işleminin amacı, dijital bir görüntüdeki tüm pikselleri çeşitli arazi örtüsü sınıflarından birine veya temalara ayırmaktır. Bu kategorize edilmiş veriler bir görüntüde bulunan arazi örtüsünün tematik haritalarını üretmek için kullanılabilir.

Normalde sınıflandırmayı gerçekleştirmek için çok bantlı (multispektral) veriler kullanılır ve aslında her piksel için verilerde bulunan spektral model, sınıflandırma için sayısal temel olarak kullanılır (Lillesand \& Kiefer, 1994). Görüntü sınıflandırmasının amacı, bir görüntüde meydana gelen özellikleri nesneye veya bu özelliklerin gerçekte zeminde temsil ettiği arazi örtüsüne göre benzersiz bir renk seviyesi olarak tanımlamak ve tasvir etmektir.

Tarımsal ürün desenlerinin belirlenmesinde, uydu görüntülerinin elde edilme tarihleri yanında bant sayıları da önemlidir (Förster vd., 2012). Bunların yanında sınıflandırma işleminde kullanılacak algoritma ve sınıflandırma yöntemi de üretilecek tematik haritanın doğruluğunu etkilemektedir. Uydu teknolojilerindeki gelişimin son yıllarda hızlanması ile birlikte UA teknolojilerinde önemli bir gelişim olmuştur. Özellikle son yıllarda yüksek çözünürlükte mekansal ve spektral bilgi üreten ve bu bilgiyi topluma sunan yüksek çözünürlüklü görüntülere paralel olarak, farklı görüntü sınıflandırma yöntemleri de geliştirilmiştir. $\mathrm{Bu}$ yöntemlerden bazıları; piksel tabanlı görüntü sınıflandırmanın yanında, nesne tabanlı görüntü sınıflandırma yöntemi ve makine öğrenme/derin öğrenme, yapay zekaya bağlı olarak yapay sinir ağları kullanılan tekniklerdir. Bu yöntemlerden biri olan, nesne tabanlı sınıflandırma yöntemi; tarımsal ürün deseninin belirlenmesi amacıyla yapılan bu çalışma için tercih edilen yöntem olmuştur.

Özellikle son yıllarda teknolojinin hızla gelişmesine bağlı olarak, uydu görüntüleri gibi dijital görüntülerin yüksek çözünürlüklü ve yoğun bilgi içeriklerine sahip veriler şeklinde elde edilmesi ve klasik piksel tabanlı sınıflandırma sonuçlarının bu yoğun verilerin işlenmesinde gösterdiği tutarsız sonuçlar karşısında, nesne tabanlı sinıflandırma yöntemi ve benzeri yöntemler daha çok tercih edilmeye başlanmıştır (Navulur, 2007). Nesne tabanlı sınıflandırma yöntemi, yüksek çözünürlüklü siyah beyaz veya çok bantlı görüntülerle iyi kullanılabildiği gibi, daha düşük mekansal çözünürlüklü görüntülerle de kullanılabilmektedir.

Nesne tabanlı sınıflandırma yöntemi; geleneksel piksel tabanlı görüntü analizine klyasla nispeten daha yakın zamanda geliştirilmiştir (Burnett \&
Blaschke, 2003). Piksel tabanlı görüntü analizi, her pikseldeki bilgilere dayanırken, nesne tabanlı görüntü analizi, nesneler veya görüntü nesneleri olarak adlandırılan benzer bir dizi pikselden alınan bilgilere dayanmaktadır. Daha spesifik olarak, görüntü nesneleri, spektral özellikler (yani renk), boyut, şekil ve doku ölçüsünün yanı sıra pikselleri çevreleyen bir komşuluk bağlamına dayalı olarak birbirine benzer piksel gruplarıdır. Bu yöntem pikselleri gruplandırarak nesneler üzerinden işlemler yapmaktadır (Şekil 2).

Nesne tabanlı sınıflandırma yönteminin ilk ve en kritik adımı segmentasyon (bölütleme) aşamasıdır (Blaschke vd., 2008; Cheng vd, 2001; Zhang, 1997). Görüntü bölütleme, nesne tabanlı sınıflandırmanın önemli bir bileșenidir. Bölütleme; bir görüntüdeki piksellerin benzer spektral ve mekansal özelliklerine sahip bölütler, nesneler veya özellikler halinde gruplandırıldığı bir işlemdir. $\mathrm{Bu}$ nesnelerin veya özelliklerin her biri birden çok piksel içermektedir. Bölütlemenin amacl, bir görüntüyü doku, renk, şekil, boyut ve gri düzeyler gibi belirli özelliklere göre farklı bir dizi ayrık bölgelere bölmektir (Lucchese \& Mitray, 2001). Görüntü bölütlemesi farklı algoritmalar kullanılarak yapılabilmektedir.

Bu çalıșmada ise, Çoklu Çözünürlüklü Bölütleme (Multiresolution Segmentation) algoritması kullanılmıştır. Bu bölütleme algoritması ölçek, şekil/renk, yoğunluk/yumuşaklık olmak üzere kullanıcı tarafindan tanımlanan 3 temel parametreden oluşmaktadır (Benz vd., 2004). Bu parametreler kullanılan uydu görüntüsünün mekansal çözünürlüğüne ve çalışllan alandaki nesnelerin (parseller) boyutuna bağlı olarak değisşkenlikler gösterebilmektedir. Ölçeğin uygun bir değerde belirlenebilmesi için objektif bir yöntem bulunmamaktadır (Kim vd., 2008). Uygun bir ölçek parametresi belirleme işlemi, literatürdeki birçok araştırmacı tarafından deneme yanılma yöntemi kullanılarak gerçekleștirilmiștir (Kavzoglu vd., 2015; Lowe \& Guo, 2011). Ölçek parametresini kullanıcı olabildiğince gerçeğe yakın değerler olarak belirlemelidir. Bu çalışmada en küçük tarım parseli boyutu dikkate alınarak ölçek parametresi belirlenmiştir. Şekil/renk ve yoğunluk/yumuşaklık parametrelerinin alacakları değerlerin toplamı 1 olmalıdır (Baatz \& Schape, 2000). Parametrelerin en uygun değerler olarak tanımlanması, bölütlerin gerçek objeleri temsil edebilme gücünü kuvvetlendirmektedir.

Bölütlemeden sonraki safha, sinıflandırma sonucunda elde edilecek arazi örtüsü veya ürün tiplerine ait sınıfların belirlenmesi aşaması olup, bunu araziden eğitim verisi olarak toplanan ürün bilgilerinin, ilgili tarım parsellerini temsil eden bölütler ile eșleştirip tanımlanması işlemi takip etmektedir.

Yönteme ait son așama, bașta mısır ekili alanlar olmak üzere ürün deseninin belirlenmesi için görüntünün sınıflandırılması aşaması olup, görüntü sınıflandırması için En Yakın Komşuluk (Nearest 
Neighbour) algoritması tercih edilmiştir. $\mathrm{Bu}$ algoritma en temel örnek tabanlı öğrenme algoritmalarından birisi olup, UA çalıșmalarında geleneksel sınıflandırıcı olarak kabul edilmiş bir algoritmadır (Çölkesen, 2015). Bu algoritma; her sınıf için seçilen örnekleri kullanıp, tüm görüntü üzerinde ortak özelliklere sahip bölütleri bularak sınıflandırma işlemini tamamlar.

Görüntü sınıflamasındaki doğruluk oranının arttırılması ve daha tutarlı bir tematik ürün deseni haritasının oluşturulması için, sınıflandırma aşamalarına yardımcı veriler eklenerek ek bilgilerle desteklenip görüntü üzerinden bilgi çıkarımı daha kolay sağlanabilmektedir. $\mathrm{Bu}$ çalıșmada ürün sınıflarının belirgin olarak ayırt edilmelerini sağlamak üzere bitki yoğunluğunu ortaya koyan bitki gelişim indislerinden normalize edilmiş fark vejetasyon indeksi olan NDVI ve ekili alanlar ile ekili olmayan alanların belirlenmesini sağlayan DDVI indisleri yardımcı veriler olarak kullanılmıştır.

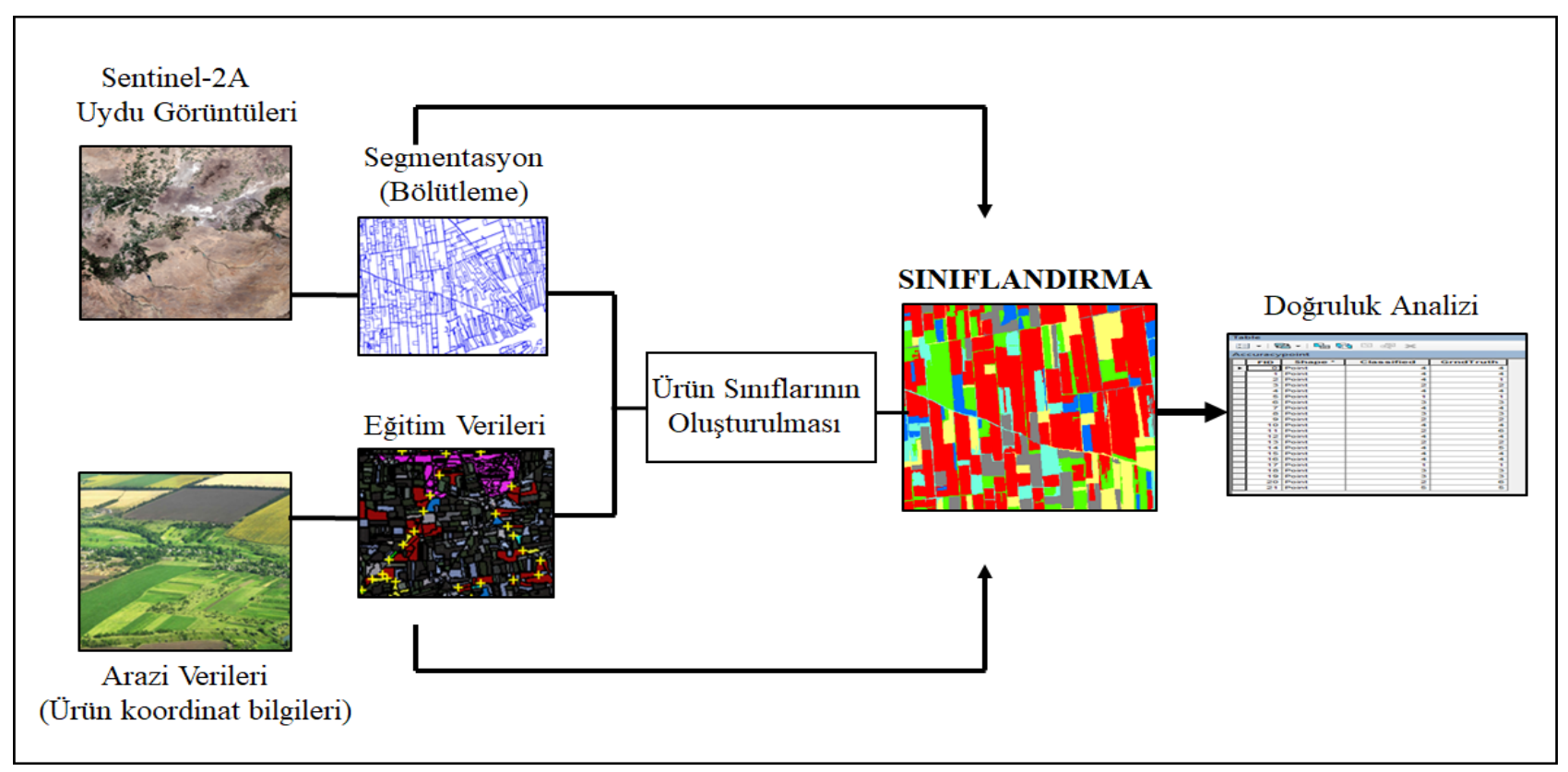

Şekil 2. Nesne tabanlı sınıflandırma yöntemi iş akış diyagramı

NDVI; Bitkiler tarafından yakın kızılötesi dalga boyundaki enerjiyi yansıtması ve görünür kırmızı dalga boyundaki enerjiyi ise absorbe etmesi temelinden yola çıkılarak geliștirilmiș olup, iklim ve insan kaynaklı tarımsal değișimleri izlemekte en yoğun kullanılan ölçütlerden biridir (Çelik \& Sönmez, 2013). UA'da yakın kızılötesi dalga boyunu yüksek oranda yansıtan bitkiler yüksek biomas (biyokütle) aktiviteye sahipken, görünür bölge olan kırmızı dalga boyunu düşük oranda yansıtan bitkiler sağlıksız ve kurudur. Bu kapsamda, NDVI görüntüleri oluşturularak bitkilerin canlı olduğu dönemler tespit edilebilmektedir (Çelik \& Karabulut, 2013). Yakın kızılötesi (NIR) ve görünür kırmızı (R) bantları arasındaki zıtlığı artırmak veya iki banttaki bilgiyi tek banta toplayarak, bitki varlığını incelemek üzere NDVI;

$$
\mathrm{NDVI}=\frac{(\mathrm{NIR}-\mathrm{R})}{(\mathrm{NIR}+\mathrm{R})}
$$

șeklinde formüle edilir.

Görüntüye ait yakın kızılötesi (NIR), görünür kırmızı (R), yeșil (G) ve mavi (B) gibi dört bantın kullanılmasıyla elde edilen DDVI indisi ise;

$$
\text { DDVI }=[(2 * \mathrm{NIR}-\mathrm{R})-(\mathrm{G}-\mathrm{B})]
$$

formülü ile tanımlanmaktadır (Deekshatulu \& Gupta, 1994; Eisfelder vd., 2009;).
Sinıflandırma sonucunda elde edilen ürün desenine ait tematik haritanın doğruluk ve güvenilirliğini test etmek, konuma dayalı olarak üretilen her türlü coğrafik veri için önemli bir adımdır. Doğruluk analizi; sınıflandırılmıș veri üzerindeki piksel veya bölütler ile referans kabul edilen bilgilerin uyumunun istatistiksel olarak karşılaştırılma ilkesine dayalı olarak test edildiği bir yöntemdir. Üretilen verinin doğruluk derecesinin belirlenmesinde en yaygın kullanılan yöntemlerden biri Kappa ( $\kappa)$ katsayısıdır. Kappa ( $($ ) katsayısı, sınıflandırmanın doğruluğunu ağırlıklı olarak hesaplayan bir istatistiksel ölçü olarak kullanılmaktadır.

Kappa (к) eșitliği aşağıdaki formül ile ifade edilmektedir:

$$
\kappa=\frac{N \sum_{i=1}^{r} x_{i i}-\sum_{i=1}^{r} x_{i+} * x_{+i}}{N^{2}-\sum_{i=1}^{r} x_{i+} * x_{+i}}
$$

r; Sinıf sayısı

$\mathrm{x}_{\mathrm{i}+}$; Satır toplamı

$\mathrm{x}_{\mathrm{ii}}$; Hata matrisinin köşegen elemanları

$\mathrm{x}_{+\mathrm{i}}$; Sütun toplamı

$\mathrm{N}$; Hata matrisindeki toplam piksel sayısı

Kappa istatistiği, istatiksel değerlendirme için kullanılan hata matrisinin satır-sütun toplamları ve köşegeni üzerindeki değerler kullanılarak elde 
edilmekte ve 0-1 arasında değer almaktadır (Richards \& Jia, 1999). Kappa ( $\kappa$ ) değerinde; 1.00 tam uyumun olduğunu, 0.75 ve fazlası sınıflandırma performansının çok iyi olduğunu, 0.40'ın aşağısı performansın yetersiz olduğunu ve 0.00 ise sınıflandırılmış veriler ile referans veriler arasındaki uyumun olmadığını göstermektedir (Mather, 1999). Doğruluk analizi için oluşturulan hata matrisinde, her bir ürün sınıfının doğruluğunun ortalama değeri olan Genel Doğruluk (GD; yüzde olarak) ile sınıflandırma doğruluğunun ağırlıklı olarak hesaplandığı Kappa Katsayısı (KK) belirlenir.

Karapınar ilçesinin 2019 yılı bitkisel üretim dönemi içerisinde ekili olan 6 farklı tarımsal ürünün (mısır, ayçiçeği, buğday-arpa, mera, pancar ve yonca- fiğ) ekimden hasata kadar olan vegetatif dönemlerinin takibi ve sinıflandırmada en uygun döneme ait kullanılacak uydu görüntüsünün tespiti için, farklı dönemlere ait 10 metre çözünürlüklü Sentinel-2A görüntüleri temin edilmiştir.

Her bir ürün tipi için seçilen örnek parsellerde 9 farklı dönem için hesaplanan NDVI indeks değerlerinin kullanılması ile ürün NDVI grafikleri oluşturulmuştur. Özellikle başta mısır ekili alanlar olmak üzere, ürün deseninin belirlenmesinde misır bitkisinin diğer tarımsal ürünlerden ayırımının daha belirgin tespit edilebilmesi açısından NDVI indeks değerinin maksimum değere ulaştığı 12 Ağustos 2019 dönemine ait uydu görüntüsü, sınıflandırmada kullanılmak üzere seçilmiştir (Şekil 3).

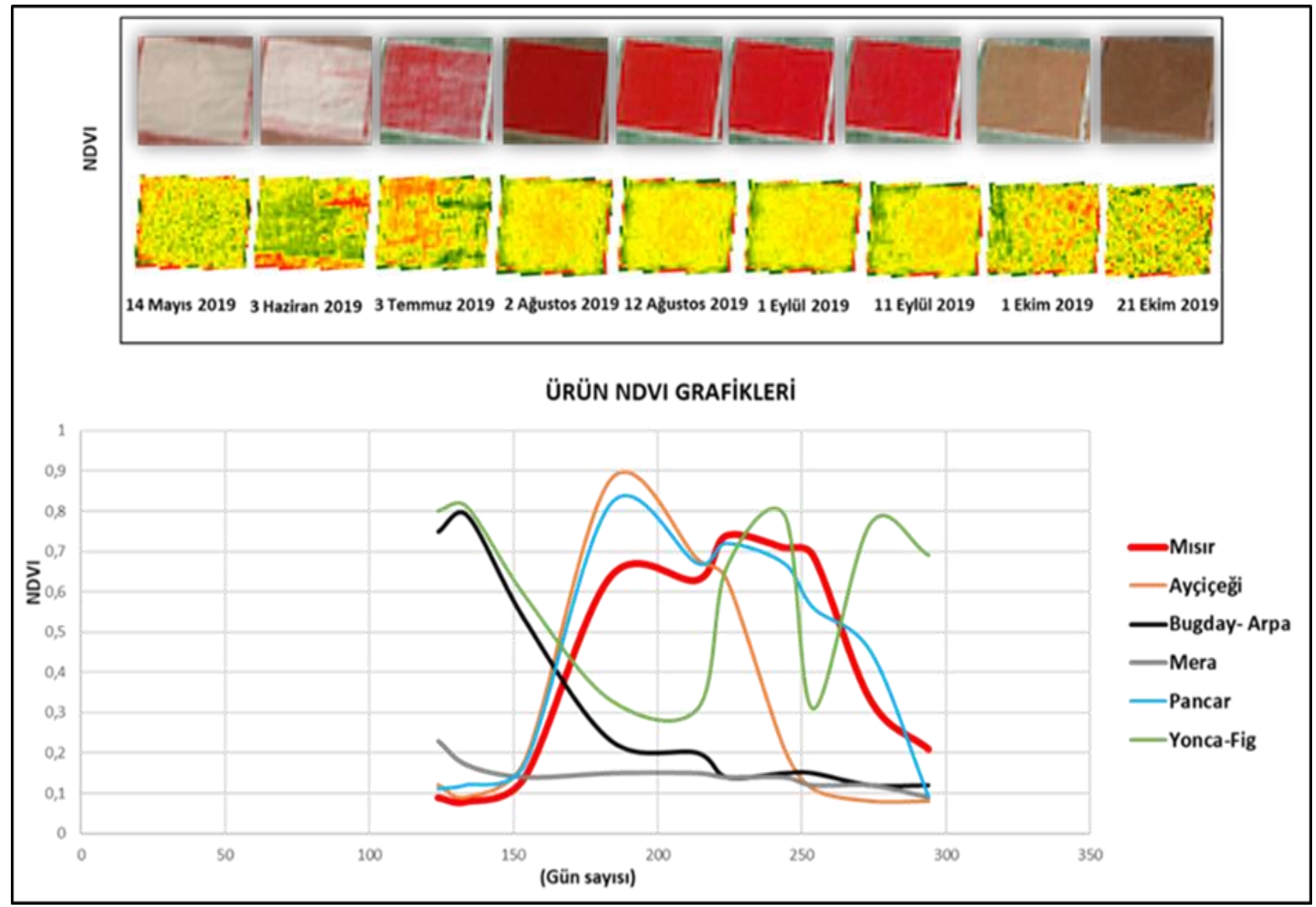

Şekil 3. Uydu görüntüsü dönemleri ve NDVI ürün grafikleri

\section{BULGULAR}

Çalışma alanını 2 adet uydu görüntüsü kaplamakta olup, bu görüntüler birleştirilmiş, çalışma alanı sınırlarınca kesilerek sınıflandırmada kullanılmıştır. $\mathrm{Bu}$ işlemler için; Coğrafi Bilgi Sistemleri (CBS) yazılımı olan ArcMap 10.5 programının eklenti modülleri kullanılmıştır.
Önce; mevcut birden fazla uydu görüntüsünü bir görüntü veri seti altında birleştirme işlemini gerçekleştirebilen Mosaic modülü kullanılarak çalışma alanını kaplayan aynı tarihli iki farklı görüntü birleştirilmiş, daha sonra ise; çlkarma (extraction) modülü ile birleştirilmiş görüntü çalışma alanı sınırları boyunca kesilmiştir (Şekil 4). 


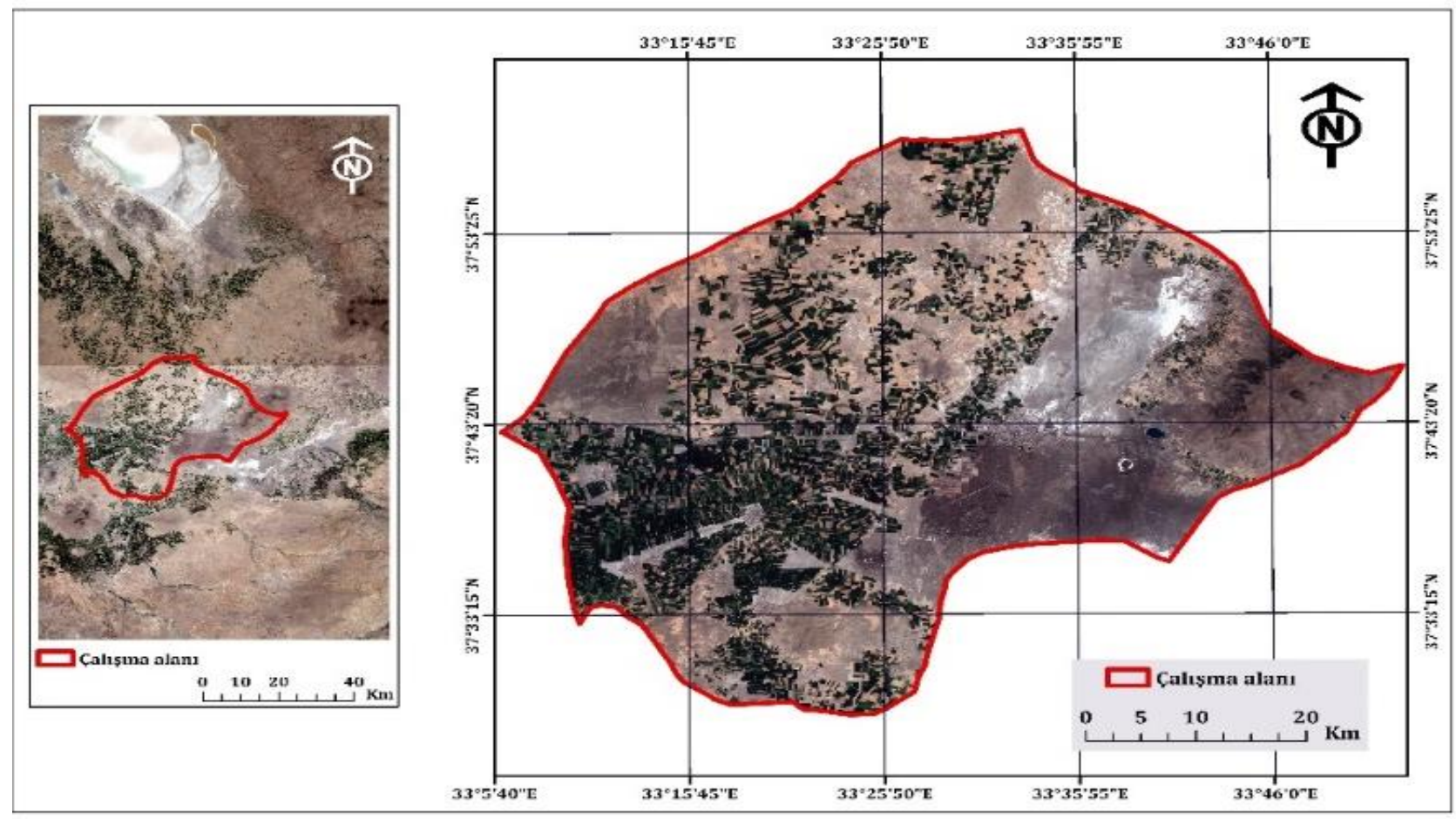

Şekil 4. Sentinel-2A uydu görüntüleri (12.08.2019)

Sinıflandırmada eğitim ve test verisi olarak kullanılmak üzere, araziden ürün koordinat bilgileri toplanmıştır. 2019 yllı Ağustos ayı içerisinde gerçekleștirilen arazi çalışmalarında, 142 adet ürün koordinat bilgileri toplanmıș olup, bu noktaların yaklaşık \% 16'sı doğrulama amacıyla test verisi olarak, geri kalan noktalar ise, sinıflandırmada eğitim verisi olarak kullanılmıștır (Şekil 5).

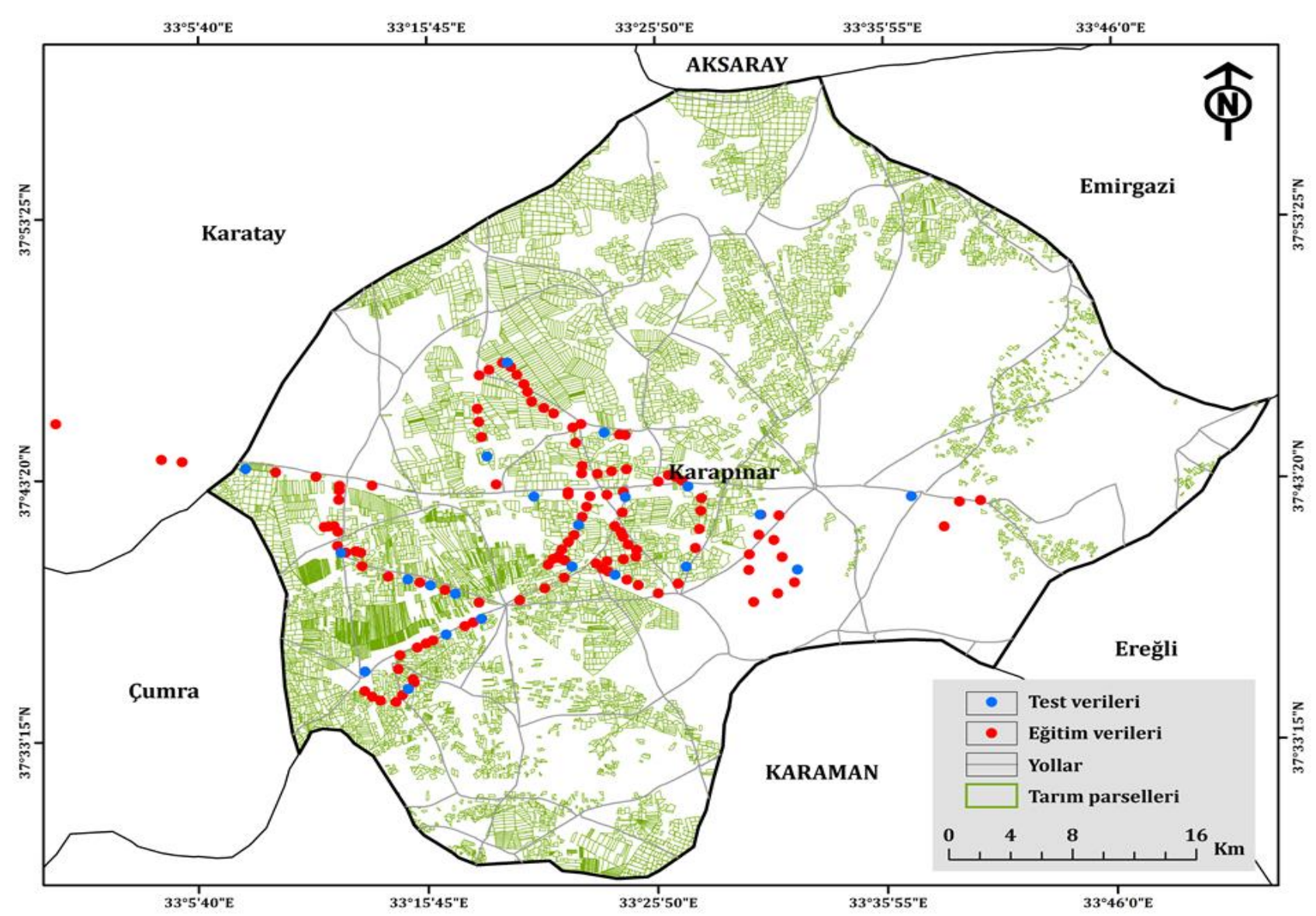

Şekil 5. Arazi verileri 
Çalışma alanı için tercih edilen çoklu çözünürlüklü bölütleme algoritması kullanılarak, Karapınar ilçesinin tarım parsellerine ait bölütler oluşturulmuştur (Şekil 6).

Bölütlere ait parametrelerden; ölçek parametresi için 200, şekil/renk için 0.3, yoğunluk/yumuşaklık için ise 0.7 değerleri en uygun değerler olarak tespit edilmiştir

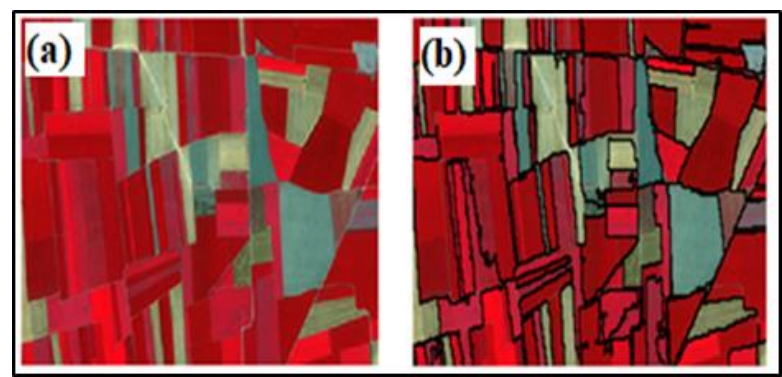

Şekil 6. (a) Orjinal uydu görüntüsü, (b) Bölütleme yapılmış uydu görüntüsü

Araziden elde edilen eğitim verilerinin oluşturulan bölütlerle eşleştirilip tanıtılması, ek bilgiler olarak NDVI ve DDVI indeksleri ile görüntünün desteklenmesinden sonra, nesne tabanlı sınıflandırmanın son aşaması olan sınıflandırma için, En Yakın Komşuluk algoritması kullanılarak görüntü sınıflandırılmış ve çalışma alanının ürün deseni tematik haritası elde edilmiştir (Şekil 7).

Sinıflandırma ile elde edilen ürün deseni haritasına göre; 2019 yllı itibariyle Karapınar ilçesinde en fazla alanı \% 58.17 oranında 127051.96 hektar ile Mera-Nadas alanları oluşturmuștur. Tarımsal ürünler arasında ise, mısır (\% 15.96) ve Buğday-Arpa (\%15.31) alanları en fazla ekim alanı bulan ürünler olmuştur (Tablo 2).

Tablo 2. Sınıflandırılan ürünlerin alansal dağılımları

\begin{tabular}{|l|c|c|}
\hline \multirow{2}{*}{\multicolumn{1}{|c|}{ ÜRÜNLER }} & GÖRÜNTÜ SINIFLANDIRMASI \\
\cline { 2 - 3 } & Alan (ha) & Alan (\%) \\
\hline Ayçiçeği & 7612.43 & 3.49 \\
\hline Buğday-Arpa & 33431.50 & 15.31 \\
\hline Mısır & 34847.29 & 15.96 \\
\hline Pancar & 6978.74 & 3.20 \\
\hline Yonca-Fĭg & 8465.34 & 3.87 \\
\hline Mera-Nadas & 127051.96 & 58.17 \\
\hline
\end{tabular}

Üretilmiş tarımsal ürün desenini gösteren tematik haritanın doğruluk ve güvenilirliğini test etmek için, ürün koordinat bilgilerine ait test verileri ile sınıflandırılmış tematik ürün deseni parsellerinin karşılaştırılmasına dayalı olarak bir hata matrisi oluşturulmuştur (Tablo 3).

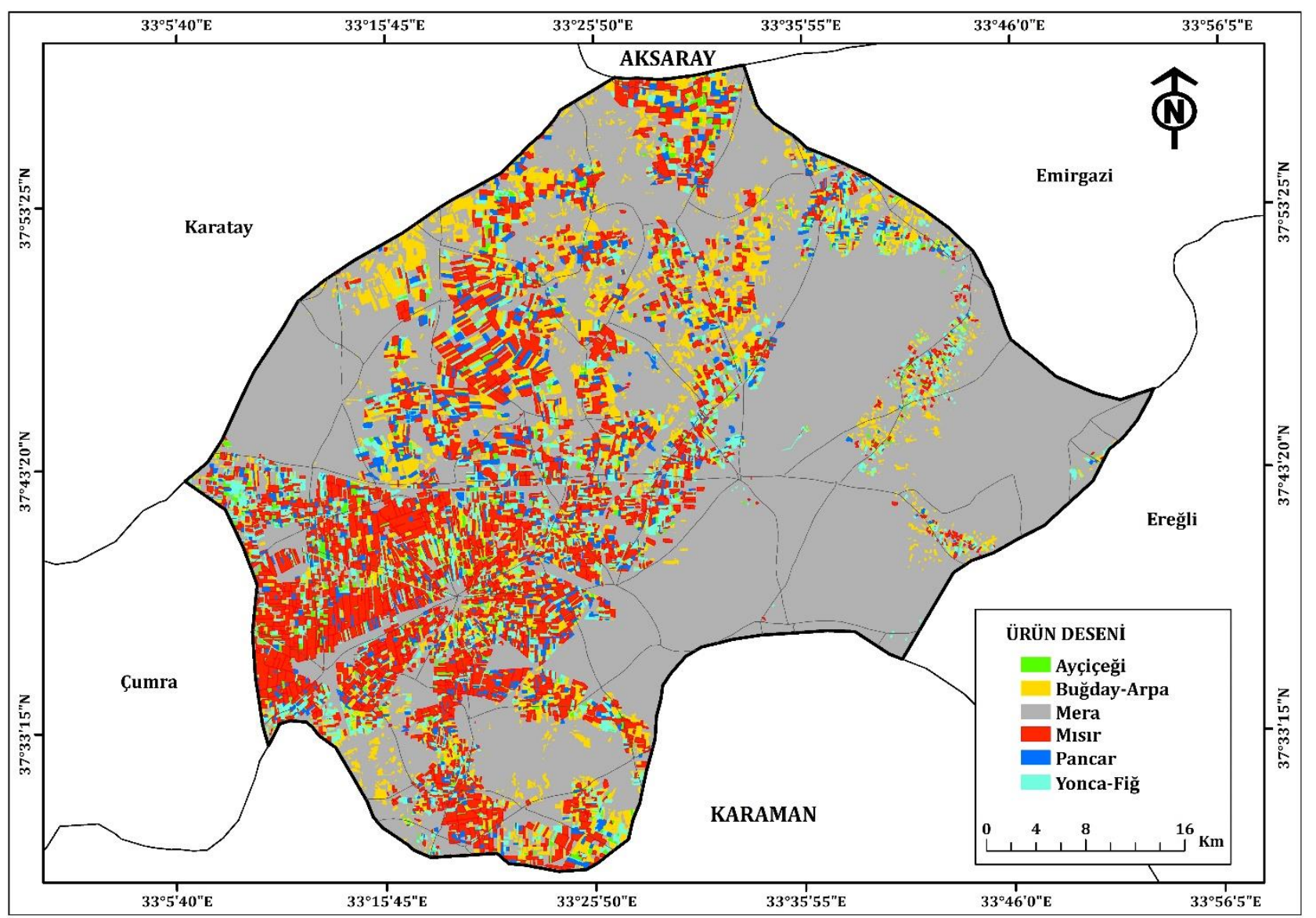

Şekil 7. Karapınar ilçesinin sınıflandırılmış ürün deseni haritası (2019 yılı)

$\mathrm{Bu}$ hata matrisinde; her bir ürün tipinden farklı sayıda seçilen test verilerinin (toplam 22 adet) sinıflandırma sonucunda elde edilen ürün deseni tematik haritasındaki ürünlerle ne oranda birebir eşleștiklerinin tespitine göre, verinin doğruluğu ve güvenirliği hesaplanmıştır. 
Alternatif olarak ürünler bazında test verilerinin sayılarındaki değişimlerin tercih edilmesi durumunda, her bir ürün tipine ait kullanıcı ve üretici doğruluklarında değișimler beklenebilir, fakat verinin genel doğruluk ve kappa katsayısında bir değişim beklenmez.

Tablo 3. Doğruluk analizi için oluşturulmuş hata matrisi

\begin{tabular}{|c|c|c|c|c|c|c|c|c|c|}
\hline SINIFLAR & Ayçiçeği & $\begin{array}{c}\text { Buğday- } \\
\text { Arpa }\end{array}$ & Mera & Misir & Pancar & $\begin{array}{l}\text { Yonca- } \\
\text { Fiğ }\end{array}$ & Toplam & $\begin{array}{c}\text { Kullanıcı } \\
\text { Doğruluğu }\end{array}$ & Карра \\
\hline Ayçiçeği & 2.00 & 0.00 & 0.00 & 0.00 & 0.00 & 0.00 & 2.00 & 1.00 & 0.00 \\
\hline $\begin{array}{l}\text { Buğday- } \\
\text { Arpa }\end{array}$ & 0.00 & 3.00 & 0.00 & 0.00 & 0.00 & 2.00 & 5.00 & 0.60 & 0.00 \\
\hline Mera & 0.00 & 0.00 & 4.00 & 0.00 & 0.00 & 0.00 & 4.00 & 1.00 & 0.00 \\
\hline Misir & 1.00 & 0.00 & 0.00 & 8.00 & 1.00 & 0.00 & 10.00 & 0.80 & 0.00 \\
\hline Pancar & 0.00 & 0.00 & 0.00 & 0.00 & 1.00 & 0.00 & 1.00 & 1.00 & 0.00 \\
\hline Yonca-Fiğ & 0.00 & 0.00 & 0.00 & 0.00 & 0.00 & 0.00 & 0.00 & 0.00 & 0.00 \\
\hline Toplam & 3.00 & 3.00 & 4.00 & 8.00 & 2.00 & 2.00 & 22.00 & 0.00 & 0.00 \\
\hline $\begin{array}{c}\text { Üretici } \\
\text { Doğruluğu }\end{array}$ & 0.67 & 1.00 & 1.00 & 1.00 & 0.50 & 0.00 & 0.00 & 0.82 & 0.00 \\
\hline Kappa & 0.00 & 0.00 & 0.00 & 0.00 & 0.00 & 0.00 & 0.00 & 0.00 & 0.76 \\
\hline
\end{tabular}

Hata matrisine göre, sinıflandırma sonucunda elde edilen ürün deseni tematik haritasının genel doğruluğu \% 82, buna karşılık gelen Kappa katsayısı ise 0.76 olarak hesaplanmıștır.

Bu sonuçlara göre test verisi ile sınıflandırılmış görüntü arasındaki uyumun çok iyi düzeyde olduğu tespit edilmiştir.

\section{SONUÇLAR}

Bu çalışma ile Konya ili Karapınar ilçesinin 2019 yılına ait bitkisel üretim sezonu içerisinde başta mısır bitkisi olmak üzere altı farklı arazi örtüsünü (mısır, ayçiçeği, buğday-arpa, mera, pancar ve yoncafiğ) içeren ürün desenine ait tematik haritası üretilmiştir. Bu tematik haritanın üretilmesinde CBS ve UA teknikleri etkin bir şekilde kullanılmıştır. Uydu görüntüsü sınıflandırılmasına dayalı olarak yapılan çalışmada, yüksek çözünürlüklü Sentinel-2A uydu görüntüleri kullanılmıştır.

Sınıflandırmayı kolaylaştırmak açısından, araziden elde edilen eğitim ve test verilerinin yanında NDVI ve DDVI gibi farklı indisler yardımcı veriler olarak kullanılmıştır. Sinıflandırma sonucunda elde edilen ürün deseni tematik haritasının doğruluk ve güvenirliliğini test etmek için bir hata matrisi olușturulmuștur. $\mathrm{Bu}$ matrise göre; sınıflandırılmış tematik haritanın Genel Doğruluğu \% 82, buna karşılık gelen Kappa Katsayısı ise, 0.76 olarak hesaplanmış ve sinıflandırma performansının çok iyi düzeyde olduğu tespit edilmiştir.

Çalışmanın sonuçlarına göre, tarımsal ürün desenlerinin belirlenmesinde nesne tabanlı sınıflandırma yönteminin yüksek doğrulukta sonuçlar verdiği görülmüştür. Daha fazla kullanılacak ek bilgilerle desteklenmesi durumunda, yöntemin doğruluk performansı arttırılabilir. Nesne tabanlı sınıflandırma yöntemine dayalı olarak yüksek doğrulukta üretilen tarımsal ürün desenleri verisi, ürünlere ait verim ve rekolte tahminleri, ürün gelişimlerinin takibi ve tarımsal planlamalar için çok önemli veriler olduğu sonucunu doğurmuştur.

\section{Bilgilendirme/Teşekkür}

$\mathrm{Bu}$ çalışma Ulusal Ürün İzleme ve Verim Tahmini projesi kapsamında yürütülmüștür. Desteklerinden dolayı Tarımsal Araştırmalar ve Politikalar Genel Müdürlüğü'ne (TAGEM) teşekkür ederiz.

\section{Araştırmacıların katkı oranı beyan özeti}

H. Torunlar \& M.G. Tuğaç: Verilerin temini, literatür taraması, araştırma yapılması, veri analizleri ve sorgulama, arazi çalışması, makalenin yazımı ve kontrol gibi bütün aşamalarda yer almışlardır.

K. Duyan: Bu makalenin oluşturulmasında sadece arazi çalışmalarında katkı sağlamıştır.

\section{Çıkar çatışması beyanı}

Makale ile ilgili olarak, herhangi bir kurum, kuruluş, kişi ile mali çıkar çatışması yoktur ve yazarlar arasında çıkar çatışması bulunmamaktadır.

\section{KAYNAKÇA}

Baatz M., \& Schape A. (2000). Multi resolution segmentation: an optimization approach for high quality multi scale image segmentation. Proceedings of Twelfth Angewandte Geographische Informations verarbeitung, Wichmann-Verlag, Heidelberg, ss.12-23.

Benz, U.C., Hofmann, P., Willhauck, G., Lingenfelder, I. \& Heynen, M. (2004). Multi- resolution, objectoriented fuzzy analysis of remote sensing data for GIS-ready information. ISPRS Journal of Photogrammetry and Remote Sensing, 58 (3), pp. 239-258. 
Blaschke, T., Lang, S., \& Hay, G.J. (Eds.) (2008). Object-based image analysis: spatial concepts for knowledge-driven remote sensing applications. Springer Science \& Business Media.

Burnett, C., \& Blaschke. T. (2003). A multi-scale segmentation/object relationship modeling methodology for landscape analysis. Ecological Modeling, 168(3), 233-249.

Chandra, A.M., \& Ghosh S.K. (2007). Remote Sensing and Geographical Information System. Alpha Science International, Oxford U.K. ss 16-24, 97 114.

Cheng, H.D., Jiang, X.H., Sun, Y., \& Wang, J. (2001). Color image segmentation: Advances and prospects. Pattern Recognition. 34(12), 22592281.

Çelik, M. A. \& Karabulut, M. (2013). Yağış koşullarının Antep fistığ (Pistacia vera L.) biomas aktivitesi ve fenolojik özelliklerine etkisinin uzaktan algllama verileri kullanılarak incelenmesi. Türk Coğrafya Dergisi, (60), 37-48.

Çelik, M.A. \& Sönmez, M. E. (2013). Kızıltepe ilçesinin tarımsal yapısındaki değişimlerin MODIS NDVI verileri kullanılarak izlenmesi ve incelenmesi. Marmara Coğrafya Dergisi, 27, 262-281.

Çölkesen, İ. (2009). Uzaktan Algılamada İleri Sınıflandırma Tekniklerinin Karşılaştırılması ve Analizi. Yüksek Lisans Tezi, Gebze Yüksek Teknoloji Enstitüsü Mühendislik ve Fen Bilimleri Enstitüsü, Kocaeli, 168s.

Çölkesen, İ. (2015). Yüksek çözünürlüklü uydu görüntüleri kullanarak benzer spektral özelliklere sahip doğal nesnelerin ayırt edilmesine yönelik bir metodoloji geliştirme. Doktora tezi, İstanbul Teknik Üniversitesi, İstanbul, 276s.

Deekshatulu, B.L. \& Gupta, R.K. (1994). Remote Sensing and Vegetation. Proceedings of the Indian National Science Academy, 60(A), 299333.

Delen, A. \& Şanll, F.B. (2017). Nesne tabanlı sinıflandırma yöntemi ile tarımsal ürün deseninin belirlenmesi. Afyon Kocatepe Üniversitesi Fen ve Mühendislik Bilimleri Dergisi, 17 (Özel Sayı), 242-247.

Drusch M., Del Bello U., Carlier S., Colin O., Fernandez V., Gascon F., Hoersch B., Isola C., Laberinti P., Martimort P., Meygret A., Spoto F., Sy O., Marchese F. \& Bargellini P. (2012). Sentinel-2: ESA's Optical High-Resolution Mission for GMES Operational Services. Remote sensing of Environment, 120, 25-36.

Eisfelder, C., Kraus, T., Bock, M., Werner, M., Buchroithner, M.F. \& Strunz, G. (2009). Towards automated forest-type mapping - a service within GSE Forest Monitoring based on SPOT-5 and IKONOS data. International Journal of Remote Sensing, 30(19), 5015 -5038.

Everitt, J.H., Yang, C. \& Deloach, C.J. (2005). Remote Sensing of Giant Reed with QuickBird Satellite
Imagery. Journal of Aquatic Plant Management, 43, 81-85.

Förster, S., Kaden, K., Foerster, M. \& Itzerott, S. (2012). Crop Type Mapping Using SpectralTemporal Profiles and Phenological Information. Computers and Electronics in Agriculture, 89, 30-40.

Kavzoglu, T., Çölkesen, I. \& Yomralıglu, T. (2015). Object Based Classification with Rotation Forest Ensemble Learning Algorithm Using Very High Resolution WorldView-2 Image. Remote Sensing Letters, 6(11), pp. 834-843.

Kim, M., Madden, M. \& Warner, T. (2008). Estimation Forest Stands with Multispectral IKONOS Imagery, Object-Based Image Analysis, Berlin, Springer, 291-307.

Lillesand, T.M., \& Kiefer, R.W., (1994). Remote Sensing and Image Interpretation, 3rd ed., 750 pp., New York.

Lowe, S.H. \& Guo, X. (2011). Detecting an optimal Scale parameter in object-oriented classification. IEEE Journal of Selected Topics in Applied Earth Observations and Remote Sensing, 4(4), pp.890-895.

Lucchese, L., \& Mitray, S.K. (2001). Color image segmentation: A state-of-the-art survey. Indian National Science Academy (INSA-A). Delhi, India, pp. 207-221.

Mather, P. M., (1999). Computer Processing of Remotely Sensed Images. An Introduction, Second Edition. 292 pp., Chichester, England.

Navulur K. (2007). Multispectral Image Analysis Using the Object-Oriented Paradigm, CRC Press, Florida, U.S.A., 184 pp.

Richards, J.A. \&, Jia, X. (1999). Remote Sensing Digital Image Analysis. An Introduction, 3rd revised and enlarged edition, $363 \mathrm{pp}$.

Vuolo, F., Immitzer, M.N.M., Atzberger, C. \& Ng, W.-T. (2018). How much does multi-temporal Sentinel-2 data improve crop type classification, International Journal of Applied Earth Observation and Geoinformation, 72, 122-130.

Wesseling, J. G. \& Fedes, R. A. (2006). Assessing crop water productivity from field to regional scale, Agricultural Water Management, 86(1), 30-39.

Zhang, Y.J. (1997). Evaluation and comparison of different segmentation algorithms. Pattern Recognition Letters, 18(10), 963-974.

URL-1: www.tuik.gov.tr [Erişim tarihi: 16.04.2021]

URL-2: https://custom-scripts.sentinelhub.com/custom-scripts/sentinel-

2/composites/

[Erişim tarihi: 22.06.2021]

URL-3: $\quad$ https://gisgeography.com/sentinel-2bands-combinations/

[Erișim tarihi: 22.06.2021]

URL-4: $\quad$ https://giscrack.com/list-of-bandcombinations-in-sentinel-2a/

[Erişim tarihi: 22.06.2021] 
URL-5: www.sentinal.esa.int

[Erişim tarihi: 02.03.2021]
URL-6: www.copernicus.eu/en

[Erişim tarihi: 20.06.2019]

(c) () ()

(C) Author(s) 2021

This work is distributed under https://creativecommons.org/licenses/by-sa/4.0/ 